\title{
Perbandingan dua jenis olahraga pada pagi dan malam hari terhadap
} kualitas tidur

\section{The comparison of two types of exercise in the morning and night to the quality of sleep}

\author{
Laily Mita Andriana ${ }^{1}$, Kunjung Ashadi ${ }^{2}$ \\ ${ }^{1,2}$ Department of Sports Coaching Education, Faculty of Sport Science, Universitas Negeri \\ Surabaya, Jl. Lidah Wetan, Surabaya, 60213, Indonesia
}

Received: 20 March 2019; Revised: 30 April 2019; Accepted: 1 May 2019

doi https://doi.org/10.29407/js unpgri.v5i1.12800

\begin{abstract}
Abstrak
Pada dasarnya manusia melalui dua fase di dalam hidupnya yaitu fase ergotropic yang mana manusia beraktivitas pada pagi hari dan fase trophotropic yaitu manusia melakukan recovery di malam hari. Penelitian ini bertujuan untuk membandingan dua jenis olahraga yang dilakukan pada pagi dan di malam hari terhadap kualitas tidur. Metode penelitian yang digunakan adalah kuantitatif dan pendekatan deskriptif dengan perlakuan one shot case study design yang menggunakan 40 mahasiswa putra sebagai subjek penelitian yang terbagi dalam empat kelompok. Untuk mengetahui perbedaan kualitas tidur pada sesi pagi dan malam hari menggunakan uji independent samples $t$ test. Berdasarkan hasil penelitian ini menunjukkan bahwa kualitas tidur pada kelompok yang yang melakukan aktivitas continuous cycling berintensitas sedang di sesi pagi dan malam hari memiliki nilai $\mathrm{P}>0,05$ dan kualitas tidur pada kelompok yang melakukan aktivitas cycling with High Intensity Interval Training (HIIT) di sesi pagi dan malam hari memiliki nilai $P<0,05$. Kesimpulan dari penelitian ini adalah tidak terdapat perbedaan yang signifikan pada kualitas tidur antara kelompok yang melakukan aktivitas continuous cycling berintesitas sedang di pagi dan malam hari namun terdapat perbedaan yang signifikan pada kualitas tidur antara kelompok yang melakukan aktivitas cycling with HIIT di pagi dan malam hari.
\end{abstract}

Kata kunci: ergotropic, kualitas tidur, olahraga malam, olahraga pagi, trophotropic.

\begin{abstract}
Basically, humans are through two phases in their lives, namely the ergotropic phase in which humans were active in the morning and the trophotropic phase in which humans do recovery at night. This study aimed to compare the two types of exercise carried out in the morning and at night to the quality of sleep. The research method used was quantitative descriptive approach with a treatment of one shot case study design by using 40 male students as subjects divided into four groups. To find out the difference in the quality of sleep during morning and night sessions, this study used t-test samples independent test. Based on the results of this study, it was shown that sleep quality of the group carrying out moderate-intensity continuous cycling activities in the morning and night sessions had $P>0.05$ and the sleep quality of the group carrying out High Intensity Interval Training (HIIT) cycling in the morning and night session had a value of $P<0.05$. The conclusion of this study was that there was no significant difference in sleep quality between the groups carrying out moderate cycling activities in the morning and night session had a value of $P<0.05$. The conclusion of this study was that
\end{abstract}

Email : lailyandriana@mhs.unesa.ac.id

p-ISSN: 2548-7833

No Handphone : +6282245253268

e-ISSN: 2477-3379 
there was no significant difference in sleep quality between the groups carrying out moderate cycling activities in the morning and night, but there were significant differences in the quality of sleep between the groups carrying out HIIT cycling activities in the morning and night.

Keywords: ergotropic, sleep quality, night sports, morning exercise, trophotropic.

\section{PENDAHULUAN}

Olahraga merupakan salah satu kebutuhan terpenting bagi kehidupan masyarakat. Olahraga merupakan suatu bentuk upaya untuk mendapatkan tubuh yang sehat dan terhindar dari berbagai macam penyakit (Anggriawan \& Ashadi, 2017). Masyarakat yang melakukan aktivitas olahraga secara teratur akan mendapatkan manfaat dalam meningkatkan dan mempertahankan kebugaran, terhindar dari berbagai macam penyakit kronis seperti obesitas, diabetes serta penyakit yang berhubungan dengan kardiovaskular (Chennaoui, Arnal, Sauvet, \& Léger, 2015).

Olahraga yang benar harus memperhatikan intensitas latihan sebab ketika melakukan olahraga tidak lepas kaitannya dengan intensitas latihan. Intensitas latihan merupakan indikator tingkat berat dan ringannya seseorang dalam melakukan aktvitas olahraga. Intensitas latihan dapat diketahui melalui jumlah denyut jantung yang merupakan suatu respons fisiologis oleh sistem kardiovaskuler saat seseorang melaksanakan aktivitas olahraga (Ashadi, 2014).

Intensitas latihan memiliki berbagai macam rentang, setiap rentang intensitas latihan memiliki tujuan dan efek yang berbeda-beda terhadap tubuh. Misalnya rentang 60-70\% merupakan rentang intensitas ringan yang memiliki tujuan olahraga daya tahan dan pembakaran lemak, rentang 70-80\% merupakan rentang intensitas sedang dengan tujuan menigkatkan kebugaran, rentang 80-90\% merupakan rentang intensitas berat yang memiliki tujuan meningkatkan kapasitas performa maksimal dan rentang 90-100\% merupakan rentang intesitas maksimal dengan tujuan meningkatkan performa maksimal dan berhubungan dengan kecepatan (Ashadi, 2014). 
Selain memperhatikan intensitas latihan saat berolahraga, seseorang akan mendapatkan manfaat yang maksimal jika melakukan aktvitas olahraga dengan cara yang tepat. Salah satunya yaitu pemilihan waktu dalam melakukan olahraga. Pada umumnya pagi hari adalah waktu yang tepat untuk melakukan aktivitas dan pada malam hari adalah waktu yang tepat untuk melakukan pemulihan. Hal ini disebabkan manusia menjalani dua fase yang berbeda dalam hidupnya yaitu fase ergotropic dimana manusia melakukan aktivitas di pagi hari selanjutnya fase trophotropic yang mana manusia melakukan pemulihan di malam hari (Sari \& Purnawati, 2017). Semakin padatnya aktivitas sehari-hari pada masyarakat saat ini mengakibatkan berkurangnya waktu untuk melakukan pemulihan dengan demikian waktu untuk melakukan aktivitas olahraga juga ikut berkurang. Akibatnya masyarakat yang sibuk di pagi hari hingga sore hari menganggap bahwa malam hari adalah waktu yang tepat untuk melakukan aktivitas olahraga. Padahal seseorang yang melakukan aktivitas olahraga di malam hari akan mendapatkan dampak yaitu terganggunya kualitas tidur. Seseorang yang melakukan olahraga mendekati waktu tidur disertai intensitas yang tinggi akan mengalami peningkatan gairah fisiologis. Gejala yang ditimbulkan berupa peningkatan denyut jantung serta peningkatan pernapasan dengan demikian dapat mengganggu aktivitas tidurnya (Kline, 2017).

Yunus (2016) menyampaikan bahwa hormon adrenalin akan mengalami peningkatan pada seseorang yang melakukan olahraga di malam hari dan menimbulkan efek berupa peningkatan denyut jantung serta suhu tubuh juga ikut meningkat, kondisi tersebut menyebabkan kualitas tidur seseorang menjadi terganggu. Pernyataan tersebut didukung dengan adanya hasil penelitian yang menyebutkan bahwa kelompok yang melakukan olahraga di malam hari mengalami kejadian insomnia. Hafid (2017) menyebutkan bahwa 24 subjek penelitian yang melakukan olahraga futsal di malam hari memberikan hasil bahwa terdapat pengaruh tingkat kelelahan akibat olahraga yang dilakukan pada malam hari dengan kejadian insomnia. 
Fakta bahwa olahraga yang dilakukan pada malam hari dapat menimbulkan efek buruk pada kualitas tidur semakin diperkuat dengan adanya hasil penelitian yang dilakukan oleh Yamanaka et al (2015) yang membandingkan kualitas tidur pada olahraga yang dilakukan pada pagi dan malam hari. Pada hasil penelitiannya menyebutkan bahwa sebanyak 22 subjek mengalami gangguan tidur setelah melakukan olahraga di malam hari. Subjek mengalami gejala seperti peningkatan denyut jantung, peningkatan suhu tubuh yang disebabkan oleh saraf simpatis yang masih aktif. Pada penelitian ini juga disarankan agar masyarakat sebaiknya menghindari aktivitas fisik di malam hari disertai intensitas yang tinggi.

Sebenarnya setelah melaksanakan aktivitas olahraga seseorang akan mengalami kerusakan pada sel-sel dan jaringan otot dengan demikian akan menimbulkan rasa lelah dan capek maka dari itu pemulihan sangat diperlukan agar terhindar dari cedera dan dampak negatif lainnya (Abdillah \& Ashadi, 2018). Pemulihan bertujuan untuk mengembalikan tubuh pada kondisi normal agar seseorang dapat melakukan aktivitas selanjutnya dengan lancar (Febrianto \& Ashadi, 2017).

Untuk mengembalikan kondisi tubuh agar kembali menjadi optimal seseorang harus melakukan pemulihan sebab setelah melakukan pemulihan seseorang akan mengalami peningkatan kondisi fisik. Seseorang yang tidak melakukan pemulihan dengan waktu yang cukup dapat mengakibatkan tubuh tidak akan siap melakukan aktivitas. Dengan demikian aktivitas menjadi terhambat serta dapat menyebabkan cedera (Wardana \& Ashadi, 2018).

Dari uraian tersebut dapat disimpulkan bahwa semakin padatnya kegiatan seseorang di pagi hingga sore hari seharusnya seseorang melakukan pemulihan yaitu dengan cara tidur. Tidur adalah salah satu cara pemulihan untuk mengembalikan stamina tubuh pada keadaan yang optimal (Sarfriyanda, Karim, \& Dewi, 2015). Tidur adalah suatu usaha untuk melepaskan kelelahan jasmani dan mental (Setyowati, 2015).

Tidur memiliki fungsi yaitu dapat memulihkan atau mengistirahatkan tubuh setelah melakukan aktivitas sehari-hari, menyeimbangkan hormon 
yang ada di dalam tubuh, sel - sel tubuh yang rusak akan diperbaiki, menjaga imunitas tubuh, daya konsentrasi akan meningkat dan terjaga (Sastrawan \& Griadhi, 2017). Manfaat dari tidur akan didapatkan oleh seseorang jika memiliki kualitas tidur yang baik. Kualitas tidur yang baik dapat memberikan kesegaran dan kebugaran saat individu tersebut terbangun di keesokan harinya (Yurintika, Sabrian, \& Dewi, 2015; Safaringga \& Herpandika, 2018).

Kebutuhan tidur setiap manusia berbeda dan dibedakan berdasarkan usia, kebutuhan tidur pada usia 18 hingga 25 tahun memiliki durasi tidur selama 7 hingga 9 jam dalam sehari (Hirshkowitz et al., 2015). Namun tidak semua orang mempunyai kualitas tidur yang baik, beberapa diantaranya memiliki hambatan dalam menjalankan tidur. Salah satu penyebab terganggunya kualitas tidur adalah padatnya aktivitas dan beban kerja yang berat sehingga mengakibatkan rasa kelelahan dan ketegangan otot. Menurut Lumantow, Rompas, \& Onibala (2016), dampak negatif akan didapatkan pada seseorang yang mempunyai kualitas tidur yang buruk. Dampak yang ditimbulkan yaitu dapat memengaruhi kondisi fisik dan dapat menyebabkan berbagai macam penyakit. Hal ini disebabkan oleh tekanan darah mengalami perubahan yang abnormal. Setelah mencermati dari uraian di atas dapat disimpulkan bahwa waktu yang tepat untuk melakukan aktivitas olahraga adalah di pagi hari sebab pada waktu ini tubuh mengalami peningkatan hormon melatonin selain itu tubuh belum mengalami kelelahan dan berada pada kondisi yang siap serta tingkat konsentrasi yang tinggi.

Saleh \& Yonas (2014) juga menambahkan bahwa seseorang yang melakukan olahraga di pagi hari akan menjalaninya dengan maksimal dan nyaman sebab pada pagi hari mempunyai udara yang bersih dan terhindar dari polusi kendaraan serta udara mengandung oksigen yang lebih banyak, seseorang akan mendapatkan manfaat sinar matahari yang mengandung vitamin $D$ selain itu di pagi hari seseorang akan melakukan olahraga dengan lebih semangat sebab telah melewati fase pemulihan di malam hari. 
Penelitian ini bertujuan untuk membandingkan nilai kualitas tidur pada dua jenis aktivitas yang dilakukan pada dua waktu yang berbeda. Aktivitas yang dimaksudkan yaitu aktivitas continuous cycling dengan intensitas sedang dan aktivitas cycling with HIIT yang menggunakan gabungan antara intensitas tinggi dan rendah yang dilakukan pada dua waktu yang berbeda yaitu pada pagi dan malam hari.

\section{METODE}

Penelitian ini menggunakan metode penelitian kuantitatif dan pendekatan deskriptif dengan menggunakan one shot case study design. Penelitian dilakukan di dalam gedung Sport Science Fitness Center (SSFC) Universitas Negeri Surabaya pada tanggal 15 Januari 2019 hingga 16 Januari 2019. Penelitian ini menggunakan sasaran penelitian mahasiswa putra dari Fakultas IImu Olahraga Universitas Negeri Surabaya yang berjumlah 40 orang dan dikelompokkan ke dalam empat kelompok. Kharakteristik subjek pada penelitian ini adalah sebagai berikut; mahasiswa putra aktif dari Fakultas IImu Olahraga Universitas Negeri Surabaya, memiliki rentang usia diantara 19 hingga 23 tahun.

Tabel 1. Pengelompokan Subjek Penelitian

\begin{tabular}{ccc}
\hline & Aktivitas & Sesi \\
\hline Kelompok 1 & Continuous cycling & Pagi \\
\hline Kelompok 2 & Continuous cycling & Malam \\
\hline Kelompok 3 & Cycling with HIIT & Pagi \\
\hline Kelompok 4 & Cycling with HIIT & Malam \\
\hline
\end{tabular}

Pada tabel 1 dijelaskan bahwa kelompok satu adalah kelompok yang melakukan aktivitas continuous cycling di sesi pagi hari, kelompok dua adalah kelompok yang melakukan aktivitas continuous cycling di malam hari, kelompok tiga adalah kelompok yang melakukan aktivitas cycling with HIIT di sesi pagi hari dan kelompok empat adalah kelompok yang melakukan aktivitas cycling with HIIT di sesi malam hari. 
Tabel 2. Program Latihan Continuous Cycling

\begin{tabular}{ccc}
\hline Tahapan aktivitas & Durasi & Intensitas \\
\hline Pemanasan & 5 menit & $60 \%-70 \% \mathrm{HR}$ \\
\hline Inti & 20 menit & $70 \%-80 \% \mathrm{HR}$ \\
\hline Pendinginan & 5 menit & $50 \%-60 \% \mathrm{HR}$ \\
\hline
\end{tabular}

Pada tabel 2 dijelaskan bahwa aktivitas continuous cycling menggunakan intensitas sedang. Sebab pada fase inti menggunakan intensitas sebesar $70 \%$ - 80\%. Pada aktivitas ini subjek melakukan olahraga dengan menggunakan sepeda statis selama 30 menit yang terdiri atas tahap pemanasan, inti dan diakhiri pendinginan. Selama beraktivitas, denyut jantung subjek penelitian selalu dimonitor dengan menggunakan heart rate detector (polar) yang digunakan untuk memastikan agar subjek selalu masuk dalam zona latihan.

Tabel 3. Program Latihan Cycling with HIIT (High Intensity Interval Training)

\begin{tabular}{|c|c|c|c|}
\hline \multicolumn{2}{|l|}{ Tahapan aktivitas } & Durasi & Intensitas \\
\hline Pemanasan & & 5 menit & $60 \%-70 \% \mathrm{HR}$ \\
\hline \multirow{2}{*}{$\begin{array}{l}\text { Inti dilakukan } \\
\text { selama } 20 \text { menit }\end{array}$} & $\begin{array}{l}\text { active } \\
\text { (sprint) }\end{array}$ & 30 detik & $80 \%-90 \% \mathrm{HR}$ \\
\hline & $\begin{array}{c}\text { b. Interval } \\
\text { (slow) }\end{array}$ & 90 detik & $50 \%-60 \% \mathrm{HR}$ \\
\hline Pendinginan & & 5 menit & $50 \%-60 \% \mathrm{HR}$ \\
\hline
\end{tabular}

Pada tabel 3 tersebut ditampilkan program latihan dengan menggunakan metode High Intensity Interval Training (HIIT). Definisi HIIT adalah gabungan dua intensitas yang terdiri atas intensitas tinggi dan diselingi dengan intensitas rendah yang dilakukan beberapa siklus serta secara berulang-ulang (Nugraha \& Berawi, 2017). Aktivitas HIIT dilakukan dengan menggunakan intensitas tinggi $80 \%-90 \%$ dan diselingi dengan intensitas rendah 50\%-60\% sebagai interval (Carneiro et al., 2018).

Instrumen yang digunakan pada penelitian ini adalah sepeda statis sebagi alat untuk melakukan aktivitas fisik, Heart rate detector (polar) untuk memonitor denyut jantung subjek agar tetap masuk dalam zona 
latihan, Untuk mengetahui kualitas tidur menggunakan kuisioner kualitas tidur yang diadopsi melalui buku yang berjudul "The sleep revolution by Ariana Huffington" kuisioner yang digunakan telah disetujui dan telah divalidasi oleh tiga dosen yang berperan sebagai validator dan kuisioner tersebut dinyatakan layak untuk dijadikan sebagai instrumen penelitian.

Prosedur penelitian pada penelitian memiliki alur sebagai berikut, membuat surat ijin penelitian, mencari subjek penelitian sebanyak 40 orang, membagi 40 subjek penelitian menjadi empat kelompok, terjun ke lapangan untuk melakukan penelitian dan pengambilan data, mengolah data penelitian menggunakan program SPSS versi 23.

Teknik analisis data yang digunakan pada penelitian ini meliputi nilai maximum, nilai minimum, rata-rata dan standar deviasi nilai kualitas tidur, uji normalitas data menggunakan saphiro wilk test, levene test untuk mengetahui homogenitas data serta menggunakan independent samples $t$ test untuk menguji beda kelompok 1 dan 2 serta kelompok 3 dan 4 .

\section{HASIL DAN PEMBAHASAN}

\section{Hasil}

Instrumen yang digunakan untuk mengukur kualitas tidur adalah kuisioner yang diadopsi melalui buku yang berjudul "The sleep revolution Ariana Huffington".

Tabel 4. Norma Penilaian Kualitas Tidur pada Kuisioner "The Sleep Revolution Ariana Huffington"

\begin{tabular}{cc}
\hline Nilai & Kategori \\
\hline $0-9$ & Sangat buruk \\
\hline $10-18$ & buruk \\
\hline $19-27$ & Baik \\
\hline $28-36$ & Sangat baik \\
\hline
\end{tabular}

Pada tabel 4 dijelaskan bahwa nilai 0-9 termasuk dalam kategori sangat buruk dan membutuhkan pengobatan dan pertolongan, nilai 10-18 masuk dalam kategori buruk dan dianjurkan untuk mengubah kebiasaan yang menyebabkan buruknya kualitas tidur, nilai 19-27 masuk dalam kategori baik namun harus lebih diperbaiki lagi agar kualitas tidur yang didapatkan lebih baik lagi, nilai 28-36 masuk dalam kategori sangat baik 
dan diwajibkan untuk selalu mempertahankan kebiasaan sehari-hari sebab tidak menimbulkan dampak pada kualitas tidur.

Tabel 5. Statistik Deskriptif Nilai Kualitas Tidur

\begin{tabular}{rrrc}
\hline & Mean \& SD & Minimum & Maximum \\
\hline Kelompok 1 & $32 \pm 1,7$ & 30 & 35 \\
\hline Kelompok 2 & $30,3 \pm 3,6$ & 26 & 35 \\
\hline Kelompok 3 & $29,8 \pm 3,3$ & 23 & 34 \\
\hline Kelompok 4 & $25,9 \pm 3,9$ & 20 & 32 \\
\hline
\end{tabular}

Pada tabel 5 dijelaskan bahwa pada kelompok satu memiliki ratarata nilai kualitas tidur sebesar 32 dengan nilai tertinggi 35 dan nilai terendah 30 , pada kelompok dua memiliki rata-rata nilai kualitas tidur sebesar 30,3 dengan nilai tertinggi 35 dan nilai terendah 26 , pada kelompok tiga memiliki rata-rata nilai kualitas tidur sebesar 29,8 dengan nilai tertinggi 34 dan terendah 23, pada kelompok empat memiliki rata-rata nilai kualitas tidur sebesar 25,9 dengan nilai tertinggi 32 dan terendah 20 .

Jika dikaitkan dengan tabel empat maka dapat disimpulkan bahwa rata-rata nilai kualitas tidur pada kelompok satu, dua, dan tiga masuk dalam kategori sangat baik namun pada kelompok empat masuk dalam kategori baik.

Tabel 6. Uji Beda Menggunakan Independent Samples T-Test

Sig. Independent samples $t$ test

\begin{tabular}{ccc}
\cline { 2 - 3 } & Kelompok 1\&2 & Kelompok 3\&4 \\
\hline $\mathbf{P}$ & 0,19 & 0,02
\end{tabular}

Setelah melihat hasil independent samples $t$ test yang ditampilkan oleh tabel enam, kelompok satu dan dua memiliki nilai $P>0,05$ yang menandakan bahwa tidak ada perbedaan yang signifikan pada kualitas tidur antara kelompok yang melakukan aktivitas continuous cycling berintensitas sedang di pagi dan malam hari. pada tabel 3 juga dijelaskan bahwa pada kelompok tiga dan empat memiliki nilai $P<0,05$ yang menandakan bahwa terdapat perbedaan yang signifikan pada nilai 
kualitas tidur antara kelompok yang melakukan aktivitas cycling with HIIT di pagi dan malam hari.

\section{Pembahasan}

Dengan semakin padatnya aktivitas yang dilakukan di pagi hingga sore hari membuat masyarakat pada zaman moderen ini memutuskan untuk melakukan olahraga di malam hari. Pada penelitian ini menunjukkan hasil bahwa nilai kualitas tidur olahraga yang dilakukan pada pagi hari lebih baik daripada nilai kualitas tidur olahraga di malam hari.

Pada penelitian ini tidak hanya mencari rata-rata nilai kualitas tidur saja, penelitian ini juga membandingkan kualitas tidur tiap kelompok. Pada kelompok yang melakukan continuous cycling berintesitas sedang di pagi dan malam hari memiliki nilai $P>0,05$ yang menandakan bahwa tidak ada perbedaan yang signifikan pada nilai kualitas tidur diantara kedua kelompok. Sedangkan pada kelompok yang melakukan cycling with HIIT di pagi dan malam hari memiliki nilai $\mathrm{P}<0,05$ yang menandakan bahwa terdapat perbedaan yang signifikan pada nilai kualitas tidur diantara kedua kelompok.

Dari hasil penelitian tentang perbandingan olahraga pagi dan malam hari terhadap kualitas tidur dapat dijelaskan bahwa, pada kelompok yang melakukan olahraga di pagi hari memiliki rata-rata nilai kualitas tidur yang lebih baik daripada kelompok yang melakukan olahraga di malam hari, hal ini dikarenakan kelompok tersebut melakukan aktivitas olahraga di waktu yang tepat. Waktu yang tepat untuk melakukan aktivitas olahraga adalah pada pagi hari karena pada pagi hari manusia melalui fase ergotropic dan selanjutnya pada malam hari melakukan pemulihan sebab pada waktu itu manusia mengalami fase trophotropic.

Pada kelompok yang melakukan aktivitas cycling with HIIT di malam hari memiliki rata-rata nilai kualitas tidur yang tidak lebih baik dibandingkan kelompok-kelompok lainnya disebabkan karena kelompok tersebut melakukan aktivitas yang berintensitas tinggi dan dilakukan di malam hari. Aktivitas fisik yang dilakukan di malam hari dan disertai dengan intensitas yang berat / tinggi dapat menyebabkan overtraining dan 
rasa capek yang luar biasa (Safaringga \& Herpandika, 2018). Dengan adanya hal tersebut dapat menurunkan kualitas tidur seseorang.

Kualitas tidur seseorang akan mengalami gangguan setelah melakukan olahraga di malam hari. Hal tersebut disebabkan seseorang yang melakukan olahraga di malam hari akan mengalami peningkatan suhu tubuh dan membutuhkan waktu yang lama untuk mengembalikan ke suhu yang normal, tidak hanya itu seseorang juga akan mengalami ketegangan pikiran dan otot serta memerlukan waktu agar otot kembali rileks (Hafid, 2017).

Salah satu faktor menurunnya kualitas tidur subjek penelitian disebabkan oleh berubahnya fungsi ritme sirkardian (jam biologis tubuh) secara mendadak. Dalam kehidupan sehari-hari aktivitas manusia tidak dapat dipisahkan dengan ritme sirkardian atau jam biologis tubuh. Ritme sirkardian berfungsi sebagai pengatur variasi harian fisiologis dan perilaku manusia seperti pola bangun dan tidur, kewaspadaan, fungsi organ serta kadar hormon (Kervezee, Shechter, \& Boivin, 2018). Selain mengatur pola bangun tidur manusia, ritme sirkardian juga mengatur aspek fisiologis tubuh manusia seperti denyut nadi, suhu tubuh dan produksi urin (Kim \& Duffy, 2018).

Ritme sirkardian akan terganggu jika seseorang mengalami perubahan waktu saat melakukan kegiatan, misalnya seperti melakukan olahraga di malam hari. Ritme sirkardian dapat terganggu karena adanya perubahan jadwal kegiatan secara mendadak misalnya seperti perputaran dinas kerja, perubahan aktivitas di pagi dan malam hari. hal tersebut mengakibatkan respon fisiologis pada tubuh manusia ikut berubah. Salah satu perubahan yang sangat menonjol adalah perubahan pada siklus bangun dan tidur seseorang (Gustimigo, 2015).

Olahraga yang dilakukan pada malam hari dapat menyebabkan pergeseran pada ritme sirkardian (jam biologis). Dampak yang diakibatkan adalah terganggunya aktivitas tidur seseorang sebab setelah melakukan olahraga di malam hari sistem saraf simpatis masih terstimulasi. Akibatnya 
setelah melakukan olahraga di malam hari seseorang akan mengalami gangguan pada tidurnya (Yamanaka et al., 2015).

Penelitian ini semakin diperkuat dan didukung dengan adanya hasil penelitian tentang dampak yang diakibatkan oleh olahraga yang dilakukan di malam hari. Pada penelitian yang dilakukan oleh Buman, Phillips, Youngstedt, Kline, \& Hirshkowitz (2014) yang membandingkan olahraga yang dilakukan dalam dua waktu yang berbeda yaitu olahraga yang dilakukan empat jam sebelum tidur dan delapan jam sebelum tidur dengan menggunakan subjek penelitian yang terdiri atas pria dan wanita. Hasil menunjukkan bahwa pada subjek berjenis kelamin pria tidak mengalami gangguan tidur setelah melakukan olahraga pada malam hari namun lain halnya dengan subjek penelitian perempuan yang mengalami gangguan tidur dan merasa tidak sehat ketika bangun keesokan harinya.

Selain berdampak pada kualitas tidur, ternyata olahraga yang dilakukan di malam hari juga berdampak pada peningkatan radikal bebas di dalam tubuh. Hal tersebut dibuktikan dengan penelitian yang dilakukan oleh Yunus, (2016) di dalam penelitiannya membandingkan olahraga malam hari yang dilakukan oleh subjek atlet dan non atlet. Hasil penelitiannya menunjukkan bahwa terdapat perbedaan yang signifikan terhadap tingginya kadar MDA plasma darah yang menyebabkan stress oksidatif hal ini terjadi pada subjek non-atlet.

\section{KESIMPULAN DAN SARAN}

\section{Kesimpulan}

Nilai kualitas tidur kelompok yang melakukan aktivitas olahraga di pagi hari lebih baik daripada nilai kualitas tidur pada kelompok yang melakukan aktivitas olahraga di malam hari. Hal ini dibuktikan dengan adanya perbedaan nilai kualitas tidur yang signifikan pada kelompok yang melakukan aktivitas cycling with HIIT di pagi dan malam hari. Namun pada penelitian ini menunjukkan tidak adanya perbedaan yang signifikan pada kelompok yang melakukan aktivitas continuous cycling berintensitas yang sedang pada pagi dan malam hari. Jadi dapat disimpulkan bahwa 
olahraga dengan intensitas tinggi yang dilakukan pada malam hari dapat berdampak pada menurunnya nilai kualitas tidur.

\section{Saran}

1. Masyarakat umum disarankan untuk menghindari berolahraga di malam hari disertai intensitas yang tinggi agar terhindar dari kualitas tidur yang buruk beserta dampak yang ditimbulkannya.

2. Jika tidak memiliki waktu luang berolahraga di pagi hari, masyarakat dapat melakukan olahraga di sore hari dengan intensitas yang sedang.

\section{DAFTAR PUSTAKA}

Abdillah, G. D., \& Ashadi, K. (2018). Pemahaman pelatih sekolah sepakbola se kota Madiun tentang physiological recovery. Jurnal Prestasi Olahraga, 3(1), 1-8. Retrieved from https://jurnalmahasiswa.unesa.ac.id/index.php/jurnal-prestasiolahraga/article/view/24138

Anggriawan, J., \& Ashadi, K. (2017). Pengetahuan Instruktur Kebugaran di Wilayah Mojokerto Tentang Alat Olahraga Gym Ball. Jurnal Prestasi Olahraga, 1(1), 1-10. Retrieved from https://jurnalmahasiswa.unesa.ac.id/index.php/jurnal-prestasiolahraga/article/view/20372

Ashadi, K. (2014). Implementasi fisiologi olahraga pada olahraga prestasi. In Pertemuan ilmiah ilmu keolahragaan nasional Univeritas Negeri Malang. Malang.

Buman, M. P., Phillips, B. A., Youngstedt, S. D., Kline, C. E., \& Hirshkowitz, M. (2014). Does nighttime exercise really disturb sleep? Results from the 2013 National Sleep Foundation Sleep in America Poll. Sleep Medicine, 15(7), 755-761. https://doi.org/10.1016/j.sleep.2014.01.008

Carneiro, M. A. S., de Oliveira, A. A., Martins, F. M., Souza, A. P., Nunes, P. R. P., \& Orsatti, F. L. (2018). High-intensity interval body weight training promotes different adaptations to combined training in body composition and muscle strength in young women. Science \& Sports, $33(3)$, https://doi.org/10.1016/J.SCISPO.2017.11.001

Chennaoui, M., Arnal, P. J., Sauvet, F., \& Léger, D. (2015). Sleep and exercise: A reciprocal issue? Sleep Medicine Reviews, 20, 59-72. https://doi.org/10.1016/j.smrv.2014.06.008

Febrianto, D. S., \& Ashadi, K. (2017). Profil strategi pemulihan secara 
fisiologi atlet sepakbola PSBI Blitar senior. Jurnal Prestasi Olahraga, 1(1), 1-10. Retrieved from https://jurnalmahasiswa.unesa.ac.id/index.php/jurnal-prestasiolahraga/article/view/20367

Gustimigo, Z. P. (2015). Kualitas Tidur Penderita Diabetes Melitus. Jurnal Majority, 4(8), 133-138. Retrieved from http://juke.kedokteran.unila.ac.id/index.php/majority/article/view/148 7

Hafid, M. A. (2017). Pengaruh tingkat kelelahan akibat aktivitas fisik malam dengan kejadian insomnia pada olahragawan futsal mahasiswa UIN Alauddin Makassar tahun 2016. Jurnal Kesehatan, 10(2), 68-75. https://doi.org/10.24252/KESEHATAN.V112.4386

Hirshkowitz, M., Whiton, K., Albert, S. M., Alessi, C., Bruni, O., DonCarlos, L., ... Adams Hillard, P. J. (2015). National Sleep Foundation's sleep time duration recommendations: methodology and results summary. Sleep Health, 1(1), 40-43. https://doi.org/10.1016/j.sleh.2014.12.010

Kervezee, L., Shechter, A., \& Boivin, D. B. (2018). Impact of Shift Work on the Circadian Timing System and Health in Women. Sleep Medicine Clinics, 13(3), 295-306. https://doi.org/10.1016/j.jsmc.2018.04.003

Kim, J. H., \& Duffy, J. F. (2018). Circadian Rhythm Sleep-Wake Disorders in Older Adults. Sleep Medicine Clinics, 13(1), 39-50. https://doi.org/10.1016/j.jsmc.2017.09.004

Kline, C. E. (2017). Exercise and Sleep. Reference Module in Neuroscience and Biobehavioral Psychology. https://doi.org/10.1016/B978-0-12-809324-5.00887-7

Lumantow, I., Rompas, S., \& Onibala, F. (2016). Hubungan kualitas tidur dengan tekanan darah pada remaja di Desa Tombasian Atas Kecamatan Kawangkon Barat. JURNAL KEPERAWATAN, 4(1), 1$6 . \quad$ Retrieved from https://ejournal.unsrat.ac.id/index.php/jkp/article/view/11905

Nugraha, A. R., \& Berawi, K. N. (2017). Pengaruh High Intensity Interval Training (HIIT) terhadap Kebugaran Kardiorespirasi. Jurnal Majority, 6(1), 1-5. Retrieved from http://juke.kedokteran.unila.ac.id/index.php/majority/article/view/152 1

Safaringga, E., \& Herpandika, R. P. (2018). Hubungan antara Kebugaran Jasmani dengan Kualitas Tidur. Jurnal SPORTIF : Jurnal Penelitian Pembelajaran, $4(2)$, 235-247. https://doi.org/10.29407/js_unpgri.v4i2.12467

Saleh, A. R., \& Yonas, Y. (2014). Perbandingan Kemampuan Daya Tahan Jantung dan Paru-Paru Antara Siswa Kelas XI pada Pembelajaran 
Pendidikan Jasmani Pagi Hari dengan Siang Hari di SMAN 1 Kediri. Jurnal Pendidikan Olahraga dan Kesehatan, 2(1). Retrieved from http://jurnalmahasiswa.unesa.ac.id/index.php/jurnal-pendidikanjasmani/article/view/9796/9557

Sarfriyanda, J., Karim, D., \& Dewi, A. P. (2015). Hubungan antara Kualitas Tidur dan Kuantitas Tidur dengan Prestasi Belajar Mahasiswa. Jurnal Online Mahasiswa (JOM) Bidang IImu Keperawatan, 2(2), 1178-1185. Retrieved from https://jom.unri.ac.id/index.php/JOMPSIK/article/view/8282

Sari, I. A. C., \& Purnawati, S. (2017). Prevalensi shift work sleep disorder pada pekerja shift malam di beberapa waralaba di Denpasar Selatan. E-Jurnal Medika Udayana, 6(7), 1-9. Retrieved from https://ojs.unud.ac.id/index.php/eum/article/view/33428

Sastrawan, I. M. A., \& Griadhi, I. P. A. (2017). Hubungan kualitas tidur dan daya konsentrasi mahasiswa program studi pendidikan dokter fakultas kedokteran Universitas Udayana. E-Jurnal Medika, 6(8), 1$8 . \quad$ Retrieved https://ojs.unud.ac.id/index.php/eum/article/view/33470/20280

Setyowati, S. (2015). The Effect of Ergonomic Gymnastics Toward Elderly Sleep Quality in Bantul Yogyakarta. In The 2nd University Research Colloquium (URECOL) 2015 (pp. 190-200). LPPM Universitas Muhammadiyah Semarang. Retrieved from https://publikasiilmiah.ums.ac.id/handle/11617/6905

Wardana, R. D. K., \& Ashadi, K. (2018). Tingkat pengetahuan dan penerapan physiological recovery atlet pencak silat Puslatcab Ponorogo. In Seminar Nasional (pp. 226-234). Malang: Universitas Negeri Malang.

Yamanaka, Y., Hashimoto, S., Takasu, N. N., Tanahashi, Y., Nishide, S., Honma, S., \& Honma, K. (2015). Morning and evening physical exercise differentially regulate the autonomic nervous system during nocturnal sleep in humans. American Journal of PhysiologyRegulatory, Integrative and Comparative Physiology, 309(9), R1112-R1121. https://doi.org/10.1152/ajpregu.00127.2015

Yunus, M. (2016). Pengaruh Aktivitas Badminton pada Malam Hari Terhadap Stres Oksidatif (Studi Kasus pada Mahasiswa Universitas Negeri Malang). Jurnal Kepelatihan Olahraga, 1(1), 1-5. Retrieved from http://journal.um.ac.id/index.php/jko/article/view/7703

Yurintika, F., Sabrian, F., \& Dewi, Y. I. (2015). Pengaruh senam lansia terhadap kualitas tidur pada lansia yang insomnia. Jurnal Online Mahasiswa (JOM) Bidang IImu Keperawatan, 2(2), 1116-1122. Retrieved from https://jom.unri.ac.id/index.php/JOMPSIK/article/view/8275 